4 Krondl, A., Vavrinkova, H., and Michalec, C., Gut, 1964, 5, 607.

5 Simmons, F., Ross, A. P. J., and Bouchier, I. A. D., Gastroenterology, $1972,63,466$

6 Shaffer, E. A., Braasch, J. W., and Small, D. M., New England Fournal of Medicine, 1972, 287, 1317.

7 Low-Beer, T. S., and Pomare, E. W., British Medical Fournal, 1973, 2, 338.

${ }^{8}$ Low-Beer, T. S., Heaton, K. W., Heaton, S. T., and Read, A. E., Lancet, 1971, 2, 991.

${ }^{9}$ Almond, H. R., Vlahcevic, Z. R., Bell, C. C. Jr., Gregory, D. H., and Swell, L., New England fournal of Medicine, 1973, 289, 1213.

10 Pomare, E. W. and Heaton, K. W., Gut, 1973, 14, 753.

11 Northfield, T. C., and Hofmann, A. F., Lancet, 1973, 1, 747.

\section{Brenner Tumours}

One of the rarer neoplasms of the ovary is the tumour first identified in 1907 by Brenner. ${ }^{1}$ Typically it is solid, resembling a fibroma in appearance, and its size varies from a microscopical lesion to a mass weighing over $8 \mathrm{~kg} .^{2}$ Microscopically the tumour consists of round or cylindrical nests of epithelial cells invested in a dense fibrocellular stroma. The epithelial cells-strikingly uniform in appearance-are large and polyhedral, and their prominent nuclei often show a characteristic longitudinal grooving reminiscent of a coffee-bean. Many of the nests have a tubular or cystic structure, and the central cavity may contain rounded protoplasmic masses superficially resembling ova. In some of these cystic spaces the superficial layer of Brenner cells may be replaced by a mucus-secreting columnar epithelium. On occasions there may be large cystic cavities lined by this mucinous epithelium to an extent that the tumour becomes indistinguishable from the common mucinous cystadenoma. It has indeed been argued that the Brenner tumour represents extensive squamous metaplasia in a mucinous cystadenoma, ${ }^{3}$ but it is much more likely that the mucinous change develops in a pre-existing Brenner tumour, since it is scanty in small tumours and most extensive in large ones. Furthermore, when mucus-secreting epithelium is present in the typical nests showing cavitation it is found centrally, which suggests that it was formed more recently than the Brenner cells.

The histogenesis of the tumour is uncertain. Brenner believed it was of follicular origin because of the ovum-like structures frequently seen in the cavities of the cell nests, ${ }^{1}$ but very few workers now accept this theory. ${ }^{4}$ Meyer ${ }^{5}$ drew attention to the similarity of the cell nests to the congenital inclusions sometimes found in the ovary called Walthard's rests; but these are also present in the Fallopian tubes and uterine ligaments, sites in which the Brenner tumour has not been described. One current view is that the tumour arises from the ovarian mesothelium (also called coelomic epithelium and germinal epithelium) which grows down in a branching fashion into the ovary and subsequently undergoes squamous and later mucoid metaplasia. Indeed some Walthard rests might develop in a similar way. The other view is that the tumour is derived from the mesonephric remnants in the ovary, the rete ovarii.

Clinically Brenner tumours usually occur in postmenopausal women. They are hormonally inert in the great majority of cases, but occasionally there is evidence of oestrogenic activity with endometrial hyperplasia. Even more rarely there may be androgenic effects. These uncommon endocrine manifestations are probably due to a transformation of the stromal cells adjacent to the epithelial nests into cells capable of producing steroids. ${ }^{2}$

Brenner tumours were originally believed to be invariably benign, but more recently an increasing number of malignant examples have been reported. In some instances the mucussecreting epithelium undergoes malignant change, when the tumour falls into the category of mucinous cystadenocarcinoma, a common type of ovarian cancer. It is, however, rarer to find authentic examples of carcinomatous change in the Brenner epithelium. ${ }^{6}$ Recently Hull and Campbell ${ }^{7}$ reported an incontrovertible case of malignant Brenner tumour occurring in a 52-year-old woman who died of multiple metastases three years after hysterectomy and bilateral oophorectomy. Histologically the tumour showed a gamut of changes extending from typically benign microcystic islets and areas of proliferating transitional epithelium to foci of anaplastic transitional-cell transformation. No mucus-secreting epithelium was present. The authors stress the strict criteria that must be applied before a malignant Brenner tumour is diagnosed. The tumour should be an anaplastic or transitional-cell carcinoma of the ovary, intimately associated with a benign Brenner tumour, and preferably showing epithelial transition. If mucinous elements are present they should be well separated from the areas of epithelial transition between the benign and malignant parts of the tumour. There should be evidence of stromal invasion, which is manifested by a gross attenuation of the stroma by extremely large epithelial masses, for cytological appearances alone are inadequate in the diagnosis of an invasive cancer. Finally there should be no evidence of a primary carcinoma in another site.

1 Brenner, F., Frankfurt Zeitschrift für Pathologie, 1907, 1, 150.

Novak, E. R., and Woodruff, J. D., Novak's Gynecologic and Obstetric Pathology, 6th edn., p. 379. Philadelphia, Saunders, 1967.

3 Woodruff, J. D., and Acosta, A. A., American Fournal of Obstetrics and Gynecology, 1962, 83, 657

4 Teoh, T. B., Fournal of Pathology and Bacteriology, 1953, 66, 441.

5 Meyer, R., Archiv für Gynäkologie, 1932, 148, 541 .

6 Idelson, M. G., Obstetrical and Gynecologic Survey, 1963, 18, 246.

7 Hull, M. G. R., and Campbell, G. R., Obstetrics and Gynecology, 1973, $42,527$.

\section{Do We Know What We Are Doing?}

Surgeons are immediately distinguishable from physicians by their extrovert attitudes and behaviour-it is in their nature to be doers rather than observers. One consequence of this difference in temperament, at least according to an American view, ${ }^{1}$ is that surgeons are less self-critical. They and their patients tend to believe that an operation must be effective, and certainly better than a pill or no treatment at all. This attitude is reflected in the papers they write, and indeed having reviewed 49 articles on cardiac surgery in 16 journals D. $H$. Spodick ${ }^{1}$ found that not one satisfied strict criteria of a scientifically designed study.

Do these conclusions apply to British medicine? The controlled clinical trial can be claimed as a British innovation. Moreover, in general the standard of assessment of the results of any form of treatment is probably higher today than 20 years ago. This owes something to high standards of refereeing by journals, education through specialist societies, and the scientific co-operation of some pharmaceutical firms. Nevertheless, a quick glance through any journal, particularly a surgical one, reveals far too many articles of the "I did this and this is what happened" variety. Such papers are sometimes necessary if they draw attention to an important unexpected occurrence, but they are worthless as part of the scientific assessment of treatment and probably do harm by publishing unsubstantiated information. 
Any study, whether a prospective trial or a retrospective review, depends upon accurate accessible records. One of the deficiencies of most British hospitals is the poor physical quality of the patient records (not their content) and the difficulty of retrieving them from storage. Whenever records are required many are found to be missing because of an inadequate tracing system. Looking at old notes is no substitute for a prospective trial, but it is often the only way in which a new thought or impression can be given substance and so developed into a hypothesis for a prospective study. Very few hospitals have any cumulative records of the effect of treatment.

It is no good improving the quality of data if there is inadequate self-criticism. This is the reason that medical schools introduce students to the problems of research and statistical evaluation and that all postgraduates are encouraged to participate in research. Experiencing the trials and tribulations of reviewing earlier publications on the subject and then setting up a valid experiment gives a young graduate a valuable insight into the problem of proving a hypothesis and a better understanding of other people's work.

But in spite of the progress in the quality of clinical research of the past 20 years doctors still tend to use unproved methods of treatment, and this is especially true of surgeons. Is this due to the differences between the mental approach of surgeons and physicians? If so it may also be said that some patients demand more "activity" than others. The tempo, temperature, and temptations of the clinical situation affect both patient and doctor, and the better the doctor's insight into these problems the easier it will be for him to compensate for them. He should reject any data that do not satisfy the strict criteria of the professional researcher and be prepared to say "no" to a patient if the evidence does not justify the patient's demands and expectations. But the patient must come first, and in the multitude of situations where adequate information does not exist surgeons and physicians will still have to act on the basis of their personal clinical experience.

${ }^{1}$ Spodick, D. M., American Heart Fournal, 1973, 85, 579.

\section{And So to Court}

It was over a year ago when the B.M.A. and the Regional Hospitals' Consultants and Specialists Association unsuccessfully attempted to resolve their differences about the repre- sentation of senior hospital doctors (Supplement 23 December 1972 , p. 103). Since then, fuelled by rising consultant discontent, the R.H.C.S.A. (from 1 April the Hospitals' Consultants and Specialists Association) has campaigned vigorously for its aim of a joint negotiating committee with the Central Committee for Hospital Medical Services. Nevertheless, Sir Keith Joseph declined to disturb the existing arrangements. The culmination was application by the R.H.C.S.A. to the National Industrial Relations Court for formal recognition in N.H.S. negotiations and a dramatic presentation in January this year of around 850 consultant resignations from the B.M.A.

There was a widespread feeling among senior hospital staff that the dispute should be settled privately within the profession. Reflecting this, the C.C.H.M.S. made a final attempt to negotiate an agreement. The outcome is described in an exchange of letters between the two organizations (Supplement, page 10). Regional consultants already have substantial membership of the C.C.H.M.S. and its subcommittees and the democratic machinery of consultant representation is open to all to use. So the B.M.A.'s offer of seats for the H.C.S.A. in the places that matter was a reasonable one. Indeed, many B.M.A. members might regard it as too generous, providing a precedent for other ginger groups of the profession to ride to power on the back of the B.M.A. In the event, the H.C.S.A. spurned the offer, demanding instead $30 \%$ of the Negotiating Subcommittee's seats pending the outcome of a joint B.M.A./H.C.S.A. inquiry into senior hospital doctor representation, or failing that independent arbitration instead of the court action. Not surprisingly the C.C.H.M.S. turned this down by a nearly unanimous vote (Supplement, p. 8)-a stand wholeheartedly supported by the Council on 4 April.

So the whole sorry business has now gone to a court whose own future is cloudy. The plight of N.H.S. consultants is widely acknowledged to be serious and B.M.A. pressure on the Government has already led to the ministerial working party on the consultant contract (to be chaired by Dr. David Owen, Parliamentary Under Secretary of State for Health). The aims of the two associations are very similar, and arguably the differences on representation are not as great as are made out. H.C.S.A. members will be deceiving themselves if they see this solely as a consultant issue. Can, then, the profession really afford an expensive, time-consuming internecine dispute at this crucial point in consultant affairs ? Few doctors will think so. 